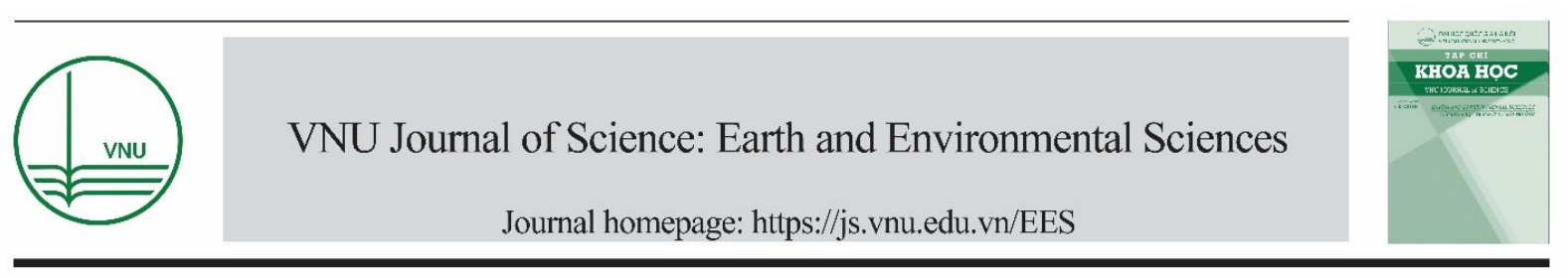

Original Article

\title{
Using IO Table in Analyzing the Environmental Burden of PET Plastic Packaging Industry in Vietnam
}

\author{
Ta Thi Yen ${ }^{1,2, *}$, Nguyen Thi Anh Tuyet ${ }^{1}$ \\ ${ }^{1}$ Hanoi University of Science and Technology, 1 Dai Co Viet, Hai Ba Trung, Hanoi, Vietnam \\ ${ }^{2}$ Hanoi University of Natural Resources and Environment, 41A Phu Dien, Tu Liem, Hanoi, Vietnam
}

Received 23 February 2020

Revised 16 April 2020; Accepted 09 June 2020

\begin{abstract}
Plastic industry plays an important role in the economic development. The PET plastic packaging industry is the largest segment of the plastic industry, accounting for $37.43 \%$ of GDP of Vietnam's plastic industry. However, the current production and consumption of PET in Vietnam are having significant environmental impacts. This study uses input-output tables (IO tables) in 2007, 2012 and updated for 2018 to determine the current status of plastic production and plastic consumption (by economic sectors) in Vietnam during the period of 2007 - 2018. At the same time, the research integrates IO tool and LCI to identify the environmental burden in the PET plastic packaging life cycle through PET's demand of other economic sectors. The results show that the two biggest PET plastic consumers are food processing sectors and electronics sectors, and these industries are also responsible for the highest indirect GHG emissions. This result can form the basis for developing a sustainable plastic packaging production and consumption strategy for Vietnam.
\end{abstract}

Keywords: IO table, LCI, plastic, emission, economic.

\footnotetext{
* Corresponding author.

E-mail address: tayen87@gmail.com

https://doi.org/10.25073/2588-1094/vnuees.4570
} 


\title{
Sử dụng bảng IO trong phân tích gánh nặng môi trường của ngành bao bì nhựa PET tại Việt Nam
}

\author{
Tạ Thị Yến ${ }^{1,2, *}$ Nguyễn Thị Ánh Tuyết ${ }^{1}$ \\ ${ }^{1}$ Viện Khoa học và Công nghệ Môi truờng, Truờng Đại học Bách khoa Hà Nội, \\ 1 Đại Cổ Việt, Hai Bà Trung, Hà Nội, Việt Nam \\ ${ }^{2}$ Khoa Môi truờng, Truoòng Đại học Tài nguyên và Môi truờng Hà Nội, \\ 41 A Phú Diến, Tù Liêm, Hà Nội, Việt Nam \\ Nhận ngày 23 tháng 02 năm 2020 \\ Chỉnh sửa ngày 16 tháng 4 năm 2020; Chấp nhận đăng ngày 09 tháng 6 năm 2020
}

\begin{abstract}
Tóm tắt: Ngành công nghiệp nhựa có vai trò quan trọng trong phát triển kinh tế. Trong đó, bao bì nhựa PET là phân khúc lớn nhất trong ngành nhựa, chiếm 37,43\% GDP của ngành nhựa Việt Nam. Tuy nhiên, hoạt động sản xuất và tiêu dùng nhựa PET hiện nay đang có những tác động môi trường đáng kể. Nghiên cứu này sử dụng các bảng cân đối liên ngành (còn gọi là bảng $\mathrm{IO}$ - input output table) các năm 2007, 2012 và cập nhật cho 2018 để xác định hiện trạng sản xuất nhựa và tiêu dùng nhựa (theo các ngành kinh tế) của Việt Nam trong giai đoạn 2007-2018. Nghiên cứu cũng đã tích hợp công cụ IO và LCI để xác định gánh nặng môi trường trong vòng đời bao bì nhựa PET thông qua nhu cầu sử dụng PET của các ngành kinh tế khác. Kết quả cho thấy nhu cầu tiêu dùng nhựa PET cao nhất thuộc về hai nhóm ngành thực phẩm và điện tử và đây cũng là hai ngành chịu phát thải gián tiếp KNK do sử dụng nhựa PET cao nhất. Kết quả này có thể làm cơ sở cho việc xây dựng chiến lược sản xuất và tiêu dùng bao bì nhựa bền vững ở Việt Nam.
\end{abstract}

Tù khoá: LCI, bảng IO, nhựa PET.

\section{Mở đầu}

Ngành công nghiệp nhựa có vai trò quan trọng trong nền kinh tế của Việt Nam. Ngành nhựa có sự đóng góp cho hầu hết các ngành kinh tế. Việc gia tăng tính bền vững của ngành công nghiệp này được đánh giá là có thể mang lại nhiều cơ hội phát triển, tăng khả năng cạnh tranh trong lĩnh vực sản xuất và tạo nhiều cơ hội việc làm.

Năm 2017, ngành nhựa đạt 15 tỷ USD chiếm 6,7\% GDP Việt nam, có tốc độ tăng trưởng sản lượng mạnh đạt 11,62\% trong giai đoạn 20122017 [1]. Nhu cầu tiêu dùng nhựa của Việt Nam cũng gia tăng từ $33 \mathrm{~kg} /$ người năm 2010 lên 41 kg/người năm 2015 [2]. Cơ cấu giá trị sản phẩm của ngành nhựa Việt Nam được chia thành 4 phân khúc chính, bao gồm: nhựa bao bì (41\%); nhựa xây dựng (24\%); nhựa dân dụng (20\%); nhựa kĩ thuật (15\%). Riêng mảng nhựa bao bì đạt 5,2 tỷ USD vào năm 2017 và tăng trưởng khoảng $11 \%$ so với 2016 [1]. Đã có nhiều nghiên cứu chỉ ra hoạt động sản xuất và tiêu dùng nhựa đã và đang tạo ra nhiều vấn đề về môi trường [3]. Hoạt động tái chế nhựa ở Việt Nam chủ yếu diễn ra ở các làng nghề với quy mô nhỏ và ảnh hưởng tiêu cực tới môi trường [4]. Hoạt động sản xuất nhựa ở Việt Nam còn phụ thuộc nhiều vào nguyên liệu nhựa nhập về từ nước ngoài (nguyên sinh và tái chế).

\footnotetext{
* Tác giả liên hệ.

Địa chi email: tayen87@gmail.com

https://doi.org/10.25073/2588-1094/vnuees.4570
} 
Những năm gần đây việc ứng dụng bảng cân đối liên ngành (còn gọi là bảng $\mathrm{IO}$ - input output table) [5] để liên kết mối quan hệ giữa kinh tế và môi trường được nhiều nhà nghiên cứu đề cập như một công cụ quan trọng trong việc nghiên cứu về phát triển bền vững của một quốc gia $[6,7]$. Đồng thời các nghiên cứu cũng đã sử dụng mô hình $\mathrm{IO}$ để phân tích mối quan hệ giữa phát triển kinh tế với việc tiêu thụ năng lượng $[8,9]$ hoặc phân tích các mối quan hệ về phát thải giữa các ngành kinh tế [10,11].

Tuy nhiên, việc lượng hóa gánh nặng môi trường trong vòng đời của sản phẩm (LCI - life cycle inventory) thông qua công cụ IO còn nhiều tiềm năng để khai thác. Tích hợp hai công cụ này cho phép ta xác định không chỉ phát thải trực tiếp và mà cả phát thải gián tiếp (thông qua mối quan hệ tương tác liên ngành). LCI là phương pháp kiểm kê phát thải của hoạt động sản xuất một sản phẩm cụ thể ra môi trường, đã và đang được áp dụng rộng rãi trên thế giới [12] và đặc biệt có hiệu quả đối với khí nhà kính (KNK) [13]. Một số nghiên cứu sử dụng LCI kết hợp với phân tích dòng vật liệu trong định lượng KNK phát thải sau tiêu dùng nhựa [14].

Nghiên cứu này khai thác công cụ IO để xác định số liệu sản xuất và tiêu dùng nhựa của các ngành kinh tế Việt Nam, sau đó tích hợp với kỹ thuật LCI để xác định gánh nặng môi trường của ngành nhựa thông qua nhu cầu sử dụng từ các ngành kinh tế khác.

\section{Phương pháp nghiên cứu}

\subsection{Sử dụng bảng IO phân tích hiện trạng sản xuất và tiêu dùng nhựa}

Bảng IO được sử dụng để ước tính số liệu sản xuất và tiêu dùng nhựa của các ngành kinh tế, đồng thời nghiên cứu sử dụng các chỉ số liên kết xuôi và liên kết ngược để phân tích vai trò của ngành nhựa tới các ngành khác.

Bảng IO phản ánh mối quan hệ giữa các ngành cung cấp hàng hóa với các ngành sản xuất ra sản phẩm hoặc dịch vụ. Giả sử nền kinh tế của một quốc gia được phân thành $\mathrm{n}$ ngành và $\mathrm{x}_{\mathrm{i}}$ là giá trị tổng sản phẩm của ngành $i, \mathrm{f}_{\mathrm{i}}$ là tổng nhu cầu cuối cùng của ngành $i$, và $z_{\mathrm{ij}}$ thể hiện giá trị mua và bán giữa ngành $i$ và $j$ thì mối quan hệ giữa các ngành được viết theo phương trình sau:

$$
\begin{gathered}
\mathrm{x}_{\mathrm{i}}=\mathrm{z}_{\mathrm{i} 1}+\ldots+\mathrm{z}_{\mathrm{ij}}+\ldots+\mathrm{z}_{\mathrm{in}}+\mathrm{f}_{\mathrm{i}}=\sum_{j=1}^{n} z_{i j}+\mathrm{f}_{\mathrm{i}} \\
(\mathrm{i}=\overline{1, n})
\end{gathered}
$$

Gọi $\mathrm{a}_{\mathrm{ij}}$ là hệ số đầu vào và đầu ra (hệ số kỹ thuật) được tính như sau:

$$
a_{i j}=\frac{z_{i j}}{X_{j}}
$$

Các hệ số này được biểu diễn tổng thể như sau:

$$
\left[\begin{array}{ccccc}
a_{11} & a_{12} & a_{13} & \ldots & a_{1 n} \\
& \ldots & \\
a_{i 1} & a_{i 2} & a_{i 3} & \ldots & a_{i n} \\
& & \ldots & & \\
a_{n 1} & a_{n 2} & a_{n 3} & \ldots & a_{n n}
\end{array}\right]=A
$$

A là ma trận hệ số kỹ thuật, ma trận cho biết giá trị sản phẩm ngành $i$ dùng để tạo ra giá trị sản xuất cho ngành $j$. Ma trận $\mathrm{A}$ phản ánh mối liên hệ giữa các ngành và quá trình công nghệ của sản xuất. Để phản ánh các mối liên kêt ngược, ma trận nghịch đảo (I-A) ${ }^{-1}$ được sử dụng - ma trận này còn có tên gọi là ma trận Leontief.

Bảng IO 2007 và 2012 của Việt Nam đã được xuất bản bởi Tổng cục Thống kê. Để theo dõi được diễn biến tiếp tục của ngành nhựa sau giai đoạn 2007-2012, nghiên cứu này đã cập nhật bảng $\mathrm{IO}$ cho năm 2018 bằng phương pháp RAS $[5,15]$. Sau đó, phân tích "độ lan tỏa" và "độ liên kết" để xác định vai trò của ngành nhựa, trên cơ sở đó xác định được sức ảnh hưởng của ngành nhựa tới các ngành kinh tế khác.

Độ lan tỏa kinh tế (liên kết ngược): dùng để đo mức độ quan trọng tương đối của một ngành với tư cách là bên sử dụng các sản phẩm vật chất và dịch vụ làm đầu vào từ toàn bộ hệ thống sản xuất so với mức trung bình của toàn nền kinh tế. Liên kết ngược được xác định bằng tỷ lệ của tổng các phần tử theo cột của ma trận nghịch đảo (ma trận Leontief) so với mức trung bình của toàn bộ hệ thống sản xuất. Tỷ lệ này còn gọi là hệ số lan tỏa và được xác định như sau:

$B L_{i}=\sum r_{i j}$ (cộng theo cột của ma trận Leontief)

$$
\text { Hệ số lan tỏa }=n \cdot \mathrm{BL}_{\mathrm{i}} / \sum B L_{i}
$$

Trong đó $r_{i j}$ là phần tử của ma trận Leontief. 
Tỷ lệ này lớn hơn 1 và càng cao có nghĩa là liên kết ngược của ngành đó càng lớn và khi ngành phát triển nhanh sẽ kéo theo sự tăng trưởng nhanh của toàn bộ các ngành cung ứng của toàn hệ thống.

Độ nhạy (liên kết xuôi): đo mức độ quan trọng của một ngành như là nguồn cung sản phẩm vật chất và dịch vụ cho toàn bộ hệ thống sản xuất. Mối liên kết này được xem là độ nhạy của nền kinh tế và được đo lường bằng tồng các phần tử theo hàng của ma trận nghịch đảo Leontief so với mức trung bình của toàn bộ hệ thống. Chỉ số liên kết xuôi được tính như sau:

$F L_{i}=\sum r_{i j}$ (cộng theo hàng của ma trận Liontief)

$$
\text { và độ nhạy }=\text { n. } F L_{i} / \sum F L_{i}
$$

Tỷ lệ này lớn hơn 1 và càng cao có nghĩa liên kết xuôi của ngành đó càng lớn và thể hiện sự cần thiết tương đối của ngành đó đối với các ngành còn lại.

\subsection{Tích hợp IO và LCI để xác định gánh nặng môi trường của ngành nhưa}

Phương pháp LCI được sử dụng để xác định hệ số phát thải của sản phẩm nhựa PET đã được công bố trong nghiên cứu trước đây [16]. Tích hợp LCI và $\mathrm{IO}$ sẽ xác định được mức phát thải gián tiếp của ngành nhựa thông qua nhu cầu sử dụng nhựa từ các ngành kinh tế khác (Hình 1).

Gánh nặng môi trường của ngành nhựa được xác định qua công thức sau:

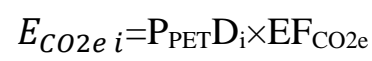

Trong đó:

$E_{C O 2 e ~} i$ : lượng khí nhà kính của ngành nhựa PET đóng góp cho ngành $i$

$P_{P E T} D_{i}$ : nhu cầu tiêu dùng nhựa $\mathrm{PET}$ của ngành $i$

$E F_{C O 2 e: ~}$ hệ số phát thải khí nhà kính của ngành nhựa PET

\section{Kết quả và thảo luận}

\subsection{Hiện trạng sản xuất và tiêu dùng nhựa}

\subsubsection{Sản lương nhưa giai đoạn 2007-2018}

Nghiên cứu sử dụng bảng cân đối liên ngành IO 2007, 2012 và cập nhật cho năm 2018 để tính toán hiện trạng sản xuất và tiêu dùng nhựa của Việt Nam. Sản lượng nhựa qua các năm được trình bày trong Hình 2.

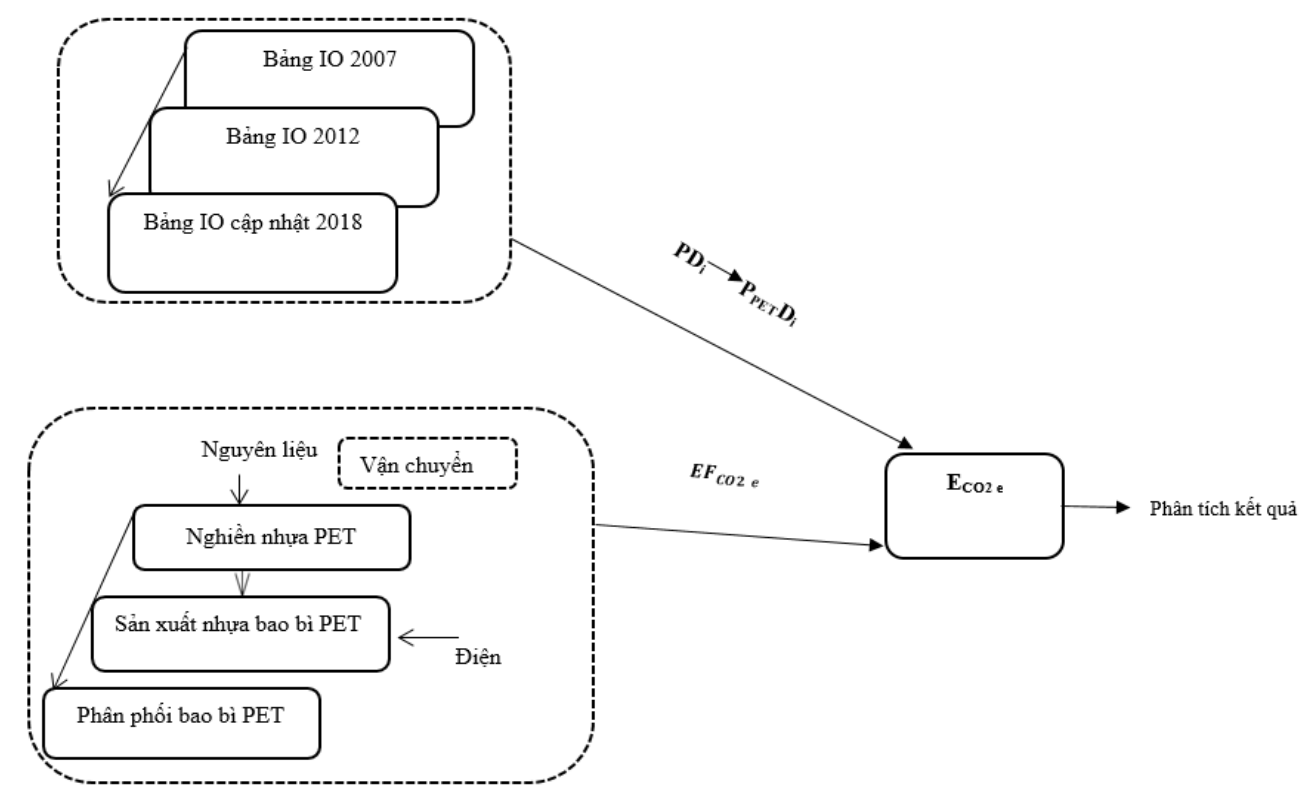

Chú thích:

$\mathrm{PD}_{\mathrm{i}:}$ Nhu cầu tiêu dùng nhựa của ngành $\mathrm{I}$;

$\mathrm{P}_{\mathrm{PET}} \mathrm{D}_{\mathrm{i}}$ : Nhu cầu tiêu dùng nhựa PET của ngành $\mathrm{i}$

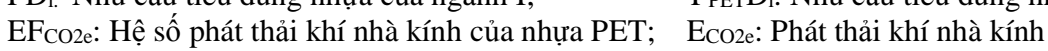

Hình 1. Sơ đồ phương pháp nghiên cứu. 


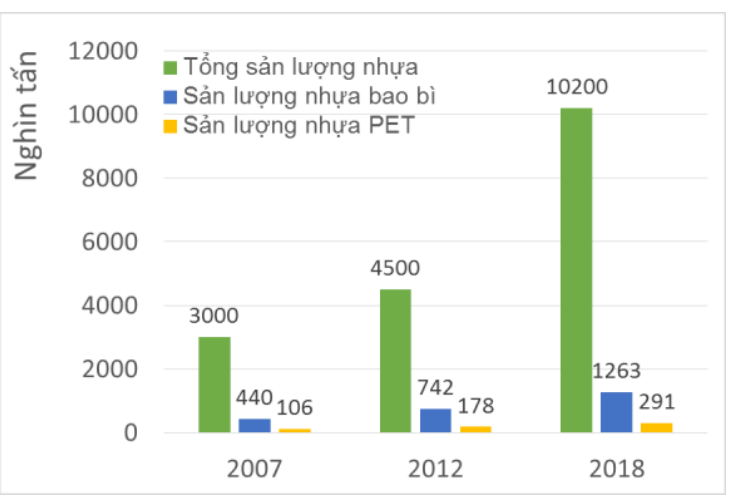

Hình 2. Hiện trạng sản xuất nhựa.

Hình 2 cho thấy sản lượng nhựa được sản xuất tăng qua các năm, đặc biệt năm 2018. Phân khúc nhựa bao bì và nhựa bao bì PET cũng tăng qua các năm. Sản lượng nhựa PET chỉ chiếm khoảng 23-24\% sản lượng nhựa bao bì. Qua đó cho thấy xu hướng ngành nhựa nói chung và ngành nhựa bao bì PET nói riêng phát triển nhanh trong giai đoạn 2007-2018.

\subsection{2. Độ lan tỏa và độ liên kết của ngành nhựa tới các ngành kinh tế khác}

Sử dụng chỉ số liên kết xuôi và liên kết ngược nghiên cứu này cũng chỉ ra rằng ngành nhựa có sự ảnh hưởng tới nhiều ngành kinh tế của Việt Nam, được chỉ ra trong Bảng 1.

Qua Bảng 1 nhận thấy ngành nông nghiệp (thủy sản, chế biến thực phẩm, chế biến rau quả, thức ăn chăn nuôi) và ngành dệt có hệ số liên kết xuôi nhỏ hơn 1 và giảm dần qua các năm, trái lại các ngành công nghiệp (nhựa, giấy, hóa chất và cao su) đều có hệ số liên kết xuôi tăng dần qua các năm. Điều này chứng tỏ có sự chuyển dịch rõ ràng từ kinh tế nông nghiệp sang công nghiệp, và các ngành công nghiệp có sự phát triển và đóng góp cho nhiều ngành kinh tế trong giai đoạn 2007-2018.

Trong giai đoạn này, ngành nhựa là một trong những ngành có chỉ số liên kết xuôi và ngược đều cao $(>1)$, điều này chứng tỏ sức ảnh hưởng của ngành nhựa tới các ngành kinh tế khác là tương đối lớn. Cụ thể, ngành nhựa có chỉ số liên kết xuôi cao, tăng mạnh và có xu hướng ổn định trong những năm gần đây $(2,107-2,646)$ cho thấy ngành này cung cấp sản phẩm quan trọng cho các ngành kinh tế khác. Đồng thời, liên kết ngược của ngành lớn hơn 1 và tăng $(1,007$ $1,211)$ chứng tỏ sự phát triển của ngành nhựa kéo theo sự phát triển của các ngành kinh tế khác, vẫn tạo động lực cho sự phát triển của các ngành kinh tế khác. Tuy nhiên, giai đoạn gần đây (2012-2018) liên kết ngược của ngành nhựa có xu hướng giảm nhẹ (1,295-1,211), điều này là do có sự thay đổi trong chính sách tiêu dùng và sản xuất các mặt hàng nhựa, đặc biệt năm 2018 với chính sách hạn chế nhập khẩu nhựa phế liệu làm cho ngành nhựa gặp phải khó khăn về nguyên liệu nhựa phế để sản xuất. Theo Hiệp hội nhựa Việt Nam, sản lượng nhựa phế liệu nhập khẩu về Việt Nam trong 6 tháng đầu năm 2018 đạt 274,7 nghìn tấn, nhưng trong 6 tháng cuối năm chỉ đạt khoảng 107 nghìn tấn [1].

Bảng 1 . Độ lan tỏa và độ liên kết của ngành nhựa tới các ngành kinh tế khác

\begin{tabular}{|c|c|c|c|c|c|c|}
\hline \multirow{2}{*}{ Tên ngành } & \multicolumn{2}{|c|}{2007} & \multicolumn{2}{c|}{2012} & \multicolumn{2}{c|}{2018} \\
\cline { 2 - 7 } & LKX & LKN & LKX & LKN & LKX & LKN \\
\hline Thủy sản & 0,554 & 1,505 & 0,533 & 1,257 & 0.407 & 1,251 \\
\hline Sản phẩm từ nhựa & 2,107 & 1,007 & 2,615 & 1,295 & 2,646 & 1,211 \\
\hline Chế biến thịt & 0,657 & 1,525 & 0,5173 & 1,456 & 0,428 & 1,340 \\
\hline Chế biến rau quả & 0,591 & 1,332 & 0,444 & 1,080 & 0.353 & 1,017 \\
\hline Bánh kẹo & 0,340 & 1,321 & 0,4014 & 1,213 & 0,308 & 1,199 \\
\hline Thức ăn chăn nuôi & 1,707 & 1,403 & 1,5937 & 1,259 & 0,969 & 1,191 \\
\hline Dệt & 0,997 & 1,464 & 0,7472 & 1,286 & 0,741 & 1,232 \\
\hline Giấy & 2,376 & 1,239 & 2,607 & 1,271 & 2,999 & 1,169 \\
\hline Hóa chất & 1,886 & 1,400 & 4,345 & 1,026 & 3,991 & 0,991 \\
\hline Cao su & 0,823 & 1,262 & 1,384 & 1,258 & 3,515 & 1,177 \\
\hline
\end{tabular}

Ghi chú: LKX: Liên kết xuôi; LKN: Liên kết ngượ. 


\subsubsection{Nhu cầu tiêu dùng nhựa}

Nhu cầu tiêu dùng nhựa trong giai đoạn 2007-2018 có xu hướng tăng lên, điều này là động lực thúc đẩy ngành nhựa phát triển mạnh. Kết quả nghiên cứu cầu tiêu dùng nhựa tính trên đầu người giai đoạn 2007-2018 (Hình 3) cho thấy nhu cầu tiêu dùng nhựa tính bình quân trên đầu người tăng từ $34.93 \mathrm{~kg} /$ người/năm ở năm 2007 và $108 \mathrm{~kg} /$ người/năm vào năm 2018. So với nhu cầu bình quân trên đầu người ở một số quốc gia thì nhu cầu tiêu dùng nhựa tại Việt Nam vẫn còn thấp hơn (Nhật Bản: 128 kg/người/năm, Mỹ: 155 kg/người/ngày, Châu Âu: 146 $\mathrm{kg} /$ người/năm [1]), do đó xu hướng ngành nhựa tại Việt Nam vẫn có triển vọng phát triển trong thời gian tới.

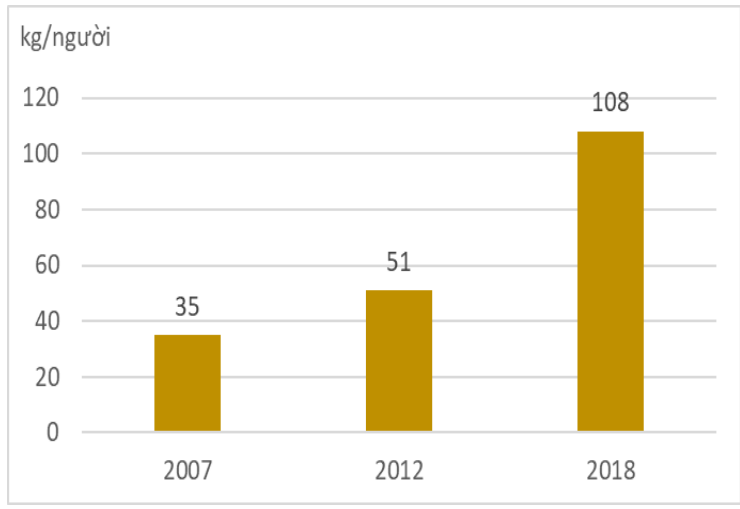

Hình 3. Nhu cầu tiêu dùng nhựa tính trên đầu người giai đoạn 2007-2018.
3.2. Nhu cầu tiêu dùng nhựa PET của các ngành kinh tế giai đoạn 2007-2018

Nhu cầu tiêu dùng nhựa $\mathrm{PET}\left(\mathrm{P}_{\mathrm{PET}} \mathrm{D}_{\mathrm{i}}\right)$ của các ngành kinh tế trong giai đoạn 2007-2018 được trình bày trong Hình 4 . Nhìn chung, hầu hết các ngành kinh tế của Việt Nam đều có nhu cầu sử dụng nhựa, đặc biệt là nhựa PET. Các nhóm ngành có nhu cầu tiêu dùng nhựa bao bì PET cao trong giai đoạn 2007-2018 là các nhóm ngành thực phẩm (ngành 35-49), nhóm ngành điện tử (ngành 62, 77-86), dịch vụ vận tải (ngành 92-94), những nhóm ngành nông lâm nghiệp (ngành 134) và nhóm ngành dịch vụ (ngành 115-164) có nhu cầu tiêu dùng nhựa PET thấp nhất. Trong đó, ngành có nhu cầu tiêu dùng nhựa PET cao nhất năm 2007, 2012 và 2018 lần lượt là ngành điện tử (ngành 62) 44.198 tấn, ngành vận tải (ngành 93) 12590 tấn và ngành điện tử (ngành 86 ) 32.026 tấn.

Trong giai đoạn 2007-2018 nhu cầu tiêu dùng nhựa PET có sự thay đổi rõ rệt. Năm 20072018 nhóm ngành điện và điện tử có nhu cầu sử dụng nhựa PET tăng cao rõ rệt vì đây là giai đoạn ngành công nghiệp điện tử có sự phát triển mạnh mẽ khi các doanh nghiệp lớn trong lĩnh vực này được chuyển từ Trung Quốc sang Việt Nam sản xuất, điều này làm gia tăng nhu cầu tiêu dùng nhựa PET của nhóm ngành này.

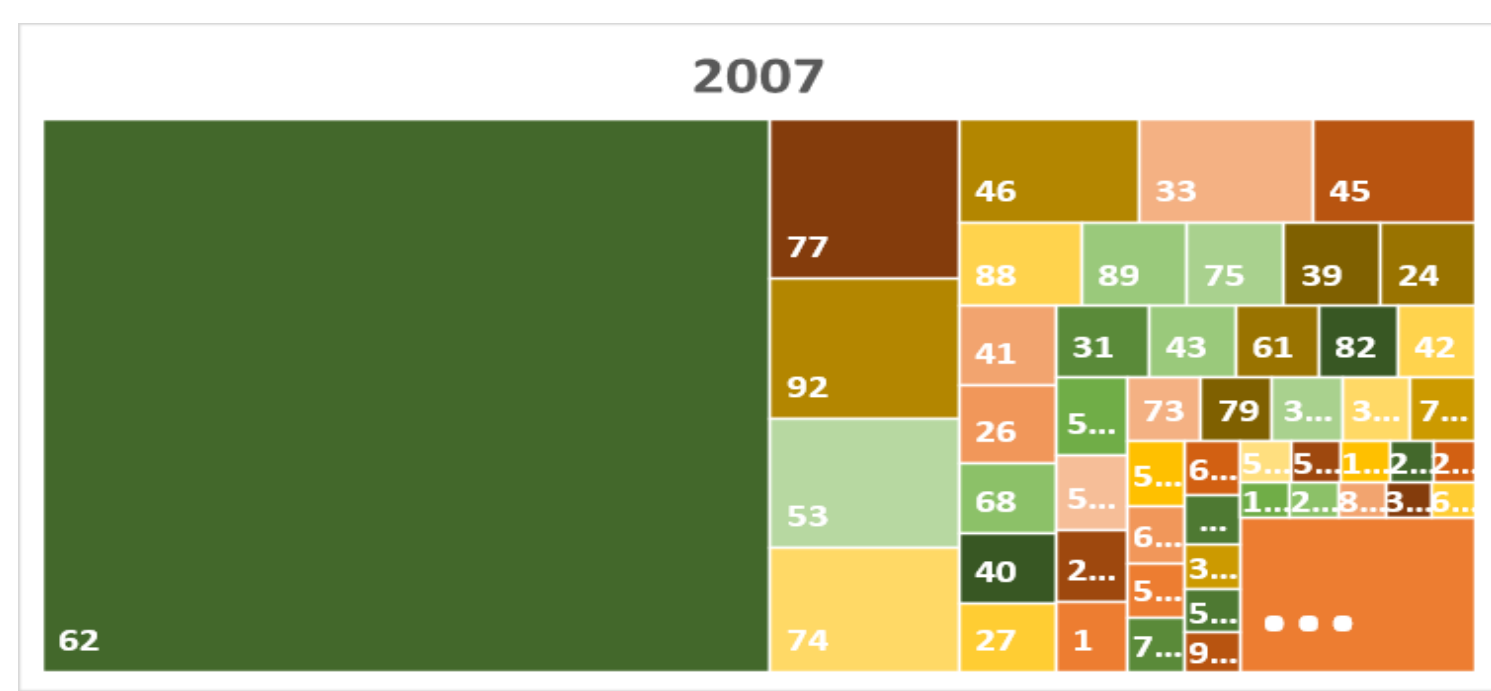

a) 


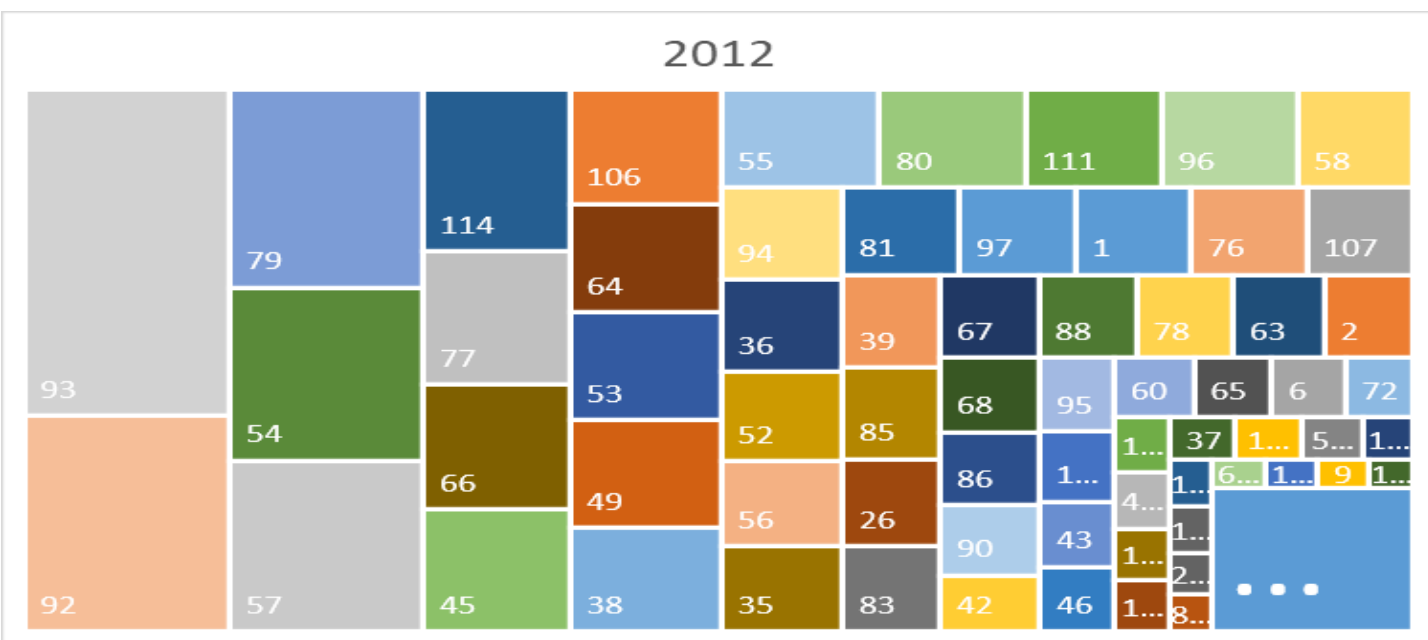

b)

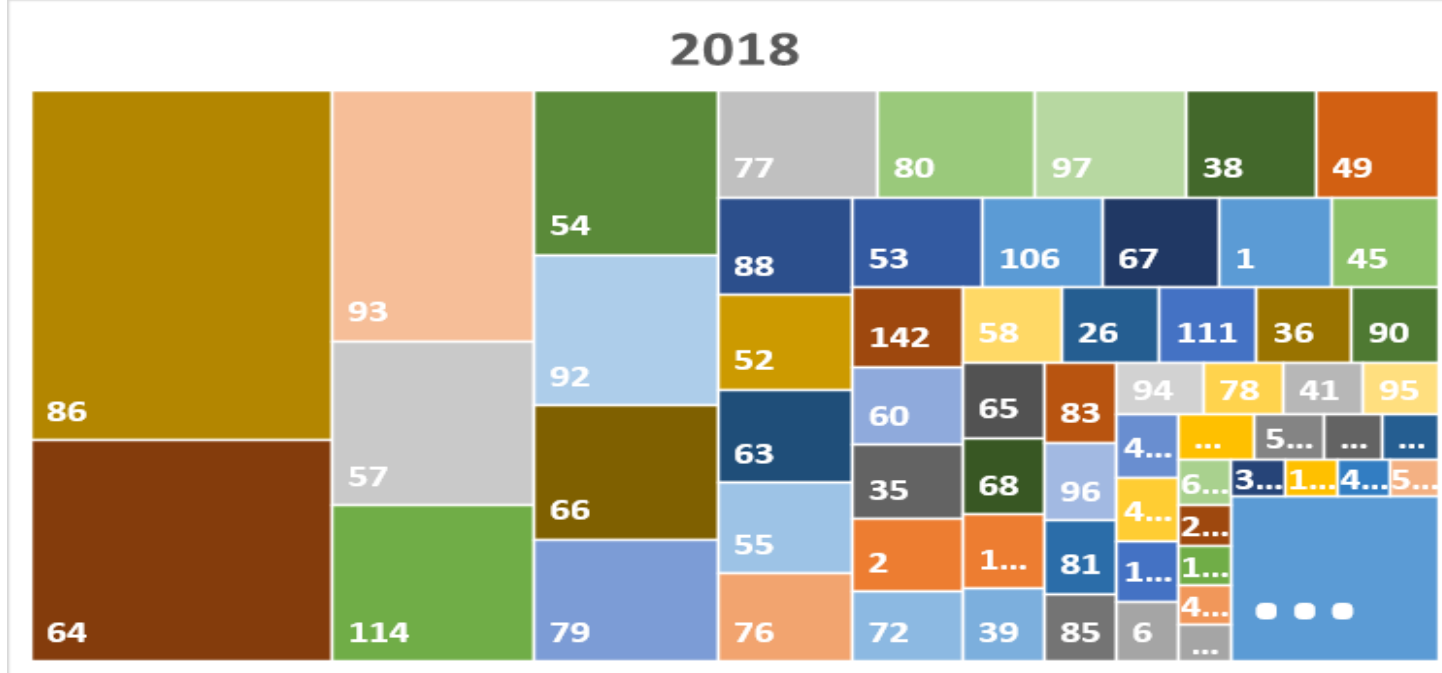

c)

Hình 4. Nhu cầu tiêu dùng nhựa PET của các ngành kinh tế trong giai đoạn 2007-2018.

3.3. Phát thải trục tiếp và gián tiếp của ngành nhựa PET tới các ngành kinh tế khác

\subsubsection{Phát thải trục tiếp}

Bằng phương pháp LCI tích hợp với IO nghiên cứu này đã xác định được gánh nặng môi trường của ngành nhựa tới các ngành kinh tế khác của Việt Nam. Hệ số phát thải khí nhà kính của ngành nhựa PET được xác định là $9.153 \mathrm{~kg}$ $\mathrm{CO}_{2} \mathrm{e} /$ tấn sản phẩm [16]. Hoạt động sản xuất bao bì nhựa PET gây phát thải trực tiếp ra môi trường lượng khí nhà kính được xác định trong Hình 5 dưới đây.

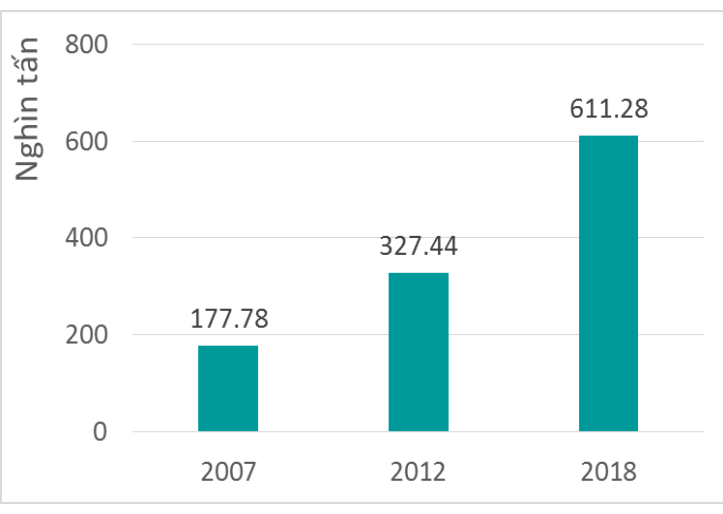

Hình 5. Phát thải trực tiếp của ngành nhựa PET. 
Qua Hình 5 nhận thấy sự phát thải khí nhà kính từ hoạt động sản xuất nhựa tăng lên qua các năm 2007-2018. Điều này là do trong giai đoạn này sản lượng sản xuất nhựa tăng đều qua các năm. Do đó cần có những hạn chế nhất định để giảm sự phát thải này ra môi trường.

\subsubsection{Phát thải gián tiếp của nhựa PET thông qua các ngành kinh tế khác}

Kết quả nghiên cứu mức đóng góp phát thải gián tiếp của bao bì nhựa PET thông qua nhu cầu sử dụng nhựa từ các ngành kinh tế khác được trình bày ở Hình 6 . Nhìn chung đóng góp phát thải của nhóm ngành nhựa PET chủ yếu tới các nhóm ngành kinh tế có nhu cầu sử dụng PET cao như nhóm ngành công nghệ chế biến thực phẩm (ngành 35-49), nhóm ngành điện tử (ngành 7786), dịch vụ vận tải (ngành 92-94). Tuy nhiên, năm 2018 do nhu cầu tiêu dùng nhựa của ngành công nghiệp điện tử gia tăng nên đóng góp phát thải của ngành nhựa PET tới nhóm ngành này cũng gia tăng hơn so với ngành khác.

Giai đoạn 2007-2018, nhìn chung đóng góp phát thải có sự gia tăng theo các năm do nhu cầu tiêu dùng nhựa PET tăng qua các năm. Kết quả của nghiên cứu này là cơ sở để định hướng phát triển ngành nhựa nói riêng và các ngành kinh tế khác nhằm mục tiêu cắt giảm khí nhà kính của hoạt động sản xuất và tiêu dùng nhựa.

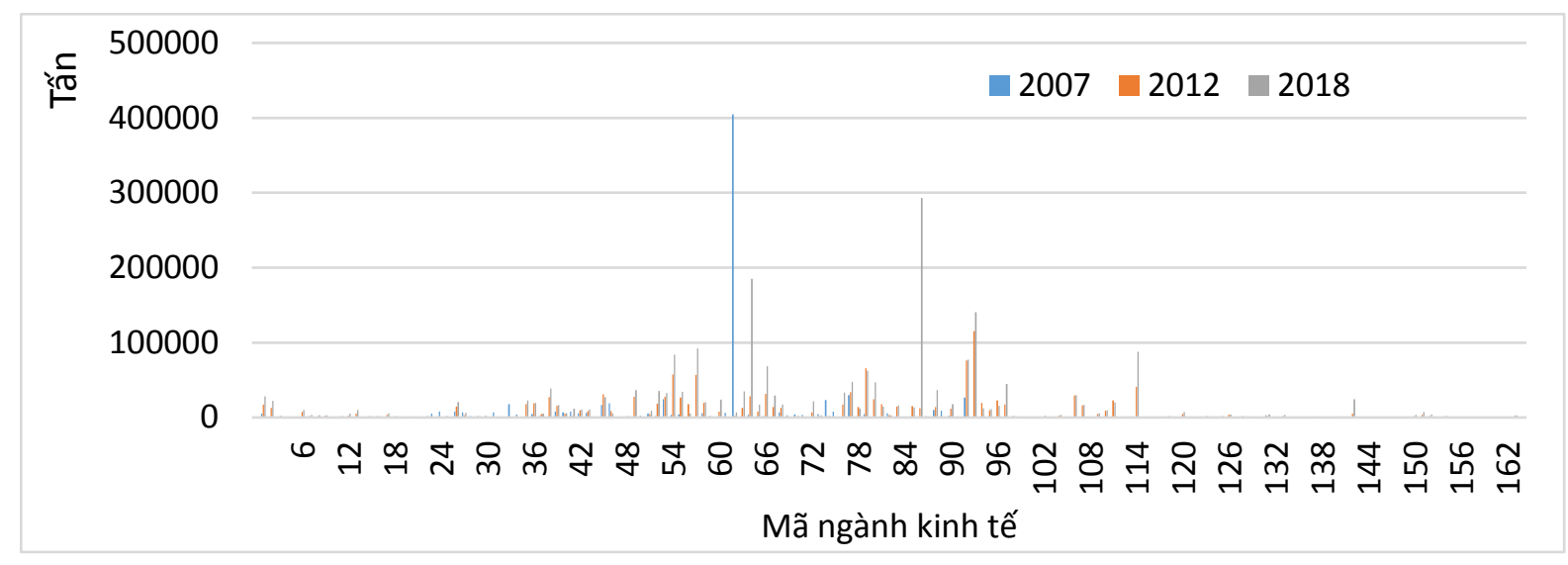

Hình 6. Phát thải gián tiếp của nhựa PET thông qua các ngành kinh tế khác.

\section{Kết luận}

Nghiên cứu này sử dụng bảng $\mathrm{IO}$ để xác định hiện trạng sản xuất và tiêu dùng nhựa trong giai đoạn 2007-2018. Đồng thời tích hợp LCI để xác định phát thải trực tiếp và gián tiếp của ngành nhựa PET Việt Nam. Kết quả cho thấy, ngành nhựa phát triển mạnh mẽ trong giai đoạn 20072018, đồng thời nhu cầu tiêu dùng nhựa cũng gia tăng qua các năm. Đóng góp phát thải gián tiếp của ngành nhựa PET chủ yếu thông qua các nhóm ngành: công nghệ chế biến thực phẩm; điện tử; và dịch vụ vận tải. Kết quả này có thể mở rộng nghiên cứu ứng dụng cho các nhóm ngành kinh tế khác, đồng thời là cơ sở đề xuất chính sách phát triển các ngành trong sự hài hòa giữa tăng trưởng kinh tế với bảo vệ môi trường.

\section{Lời cảm ơn}

Nghiên cứu này được thực hiện tại Viện Khoa học và Công nghệ Môi trường, Trường Đại học Bách Khoa Hà Nội, trong khuôn khổ đề tài B2017-BKA-42.

\section{Tài liệu tham khảo}

[1] Vietnam Plastic Association, Plastic industry report 2018 (2018) (in Vietnamese)

[2] Vietnam Plastic Association, Plastic industry report 2016 (2016) (in Vietnamese) 
[3] Dang Kim Chi, The problem "white pollution", Vietnam Journal of Science, Technology and Enginering 7A (2018) 40-42. https://vjst.vn/vjsta/ view-pdf/83/0 (accessed 10 March 2020).

[4] N.T.K. Thai, L.T.M. Huong, Assess the status of solid waste management in scrap recycling villages and propose management solutions, Journal of Science and Technology in Civil Enginering 5 (2011) 114-120 https://stce.nuce.edu. vn/index.php/vn/article/view/901 (accessed 13 March 2020)

[5] R.E. Miller, P.D. Blair, Input-output analysis: foundations and extensions, Cambridge university press, 2009.

[6] L.B. Cui, P. Peng, L. Zhu, Embodied energy, export policy adjustment and China's sustainable development: a multi-regional input-output analysis, Energy 82 (2015) 457-467. https://doi. org/10.1016/j.energy.2015.01.056.

[7] Q. Chen, K. Zhu, P. Liu, X. Chen, K. Tian, L. Yang, C. Yang, Distinguishing China's processing trade in the world input-output table and quantifying its effects. Economic Systems Research 31 (2019) 361-381. https://doi.org/10. 1080/09535314.2018.1534225.

[8] N.T.A. Tuyet, K.N. Ishihara, Analysis of changing hidden energy flow in Vietnam. Energy Policy 34 (2006) 1883-1888. https://doi.org/10.1016/j.enpol. 2005.01.011.

[9] S. Chen, B. Chen, Urban energy consumption: different insights from energy flow analysis, input-output analysis and ecological network analysis. Applied Energy 138 (2015) 99-107. https://doi.org/10.1016/j.apenergy.2014.10.055.
[10] S. Nakamura, Y. Kondo, Waste input-output analysis: concepts and application to industrial ecology. Vol. 26, Springer Science \& Business Media, 2009.

[11] C. Guo, J. Xu, L. Yang, X. Guo, J. Liao, X. Zheng, Z. Zhang, X. Chen, K. Yang, M. Wang, Life cycle evaluation of greenhouse gas emissions of a highway tunnel: A case study in China. Journal of cleaner production 211 (2019) 972-980. https:// doi.org/10.1016/j.jclepro.2018.11.249.

[12] M.A. Curran, Life cycle assessment handbook: a guide for environmentally sustainable products, John Wiley \& Sons, 2012.

[13] T.C. Chen, C.F. Lin, Greenhouse gases emissions from waste management practices using Life Cycle Inventory model, Journal of Hazardous Materials 155 (2008) 23-31. https://doi.org/10. 1016/j.jhazmat.2007.11.050

[14] E. Sevigné-Itoiz, C.M. Gasol, J. Rieadevall, X. Gabarrell, Contribution of plastic waste recovery to greenhouse gas (GHG) savings in Spain. Waste management 46 (2015) 557-567. https://doi.org/ 10.1016/j.wasman.2015.08.007.

[15] B. Trinh, N.V. Phong, A short note on RAS method. Advances in Management and Applied Economics 3 (2013) 133. https://www.research gate.net/profile/Bui_Trinh/ publication/308018908_ A_Short_Note_on_RAS_Method/links/587799a108 ae8fce492fc5b1/A-Short-Note-on-RAS-Method.pdf.

[16] T.T. Yen, N.T.A. Tuyet, Life cycle inventory for PET packages in the intergration with IO table of Vietnam. Vietnam Journal of Science and Technology 56 (2018) 111-117. https://doi.org/10. 15625/2525-2518/56/2C/13037. 